\title{
Experiências e formação docente face à inclusão de estudantes com deficiência no ensino técnico
}

DOI 10.23864/CPP-V2-N1-147

Cláudia Marisa Ferreira Machado Pimenta

Allan Rocha Damasceno

Amparo Villa Capolillo

\section{Resumo}

A inclusão de estudantes com deficiência está legitimada em vários dispositivos legais nacionais e internacionais que preconizam sua matrícula na rede regular de ensino, o que vem proporcionando um aumento significativo do número de estudantes com deficiência nas instituições de ensino. No entanto, várias são as barreiras que impedem ou dificultam a sua inclusão nessas instituições, dentre elas a própria formação docente, que podem conduzir às diversas manifestações de preconceito. Essas barreiras reiteram e levantam uma problematização a ser evidenciada por meio de pesquisas que objetivem investigar o processo de inclusão de estudantes com deficiência nas Instituições de Ensino, sentido que se fundamenta esta pesquisa. Este artigo tem como objetivo investigar o processo de inclusão de estudantes com deficiência visual na escola, a aceitação da diferença e da diversidade, tendo como base a formação e as experiências de docentes do Ensino Técnico de uma Instituição Federal de Educação do Estado de Minas Gerais. O estudo, de cunho qualitativo, teve os dados coletados por meio de entrevista semiestruturada e contou com sete professoras que atuavam com estudantes com deficiência visual como sua população-alvo. Esta pesquisa apontou a carência de uma reflexão crítica quanto à organização de escolas inclusivas e ainda uma escassez de estudos resultantes de experiências escolares sobre a educação dos estudantes com deficiência na perspectiva da inclusão escolar no Brasil, sobretudo em interface com a Educação Profissional.

Palavras-chave: Inclusão. Estudantes com deficiência. Formação docente. 


\section{Experiences and training teachers to include students with disabilities in technical education}

DOI 10.23864/CPP-V2-N1-147

Cláudia Marisa Ferreira Machado Pimenta

Allan Rocha Damasceno

Amparo Villa Capolillo

\section{Abstract}

The inclusion of students with disabilities is legitimized in several national and international legal provisions which call for their enrollment in regular education system. This is providing a significant increase in the number of student enrollments with disabilities in educational institutions. However, there are several barriers that prevent or make the entry of such students in these institutions harder. One of these barriers is teacher training, which can lead to various manifestations of prejudice, and the rejection of differences and diversity present in humans. These barriers reiterate and raise a problem to be evidenced through to conduct research that investigates the process of inclusion of students with disabilities in educational institutions, and that is what this research is based on. This article's goal is to investigate the process of inclusion of students with a visual impairment in school, and the acceptance of difference and diversity, based on the training and experience of teachers of Technical Education of the federal education institution in the State of Minas Gerais. The qualitative study includes data collected through semistructured interviews with seven teachers who worked with students with visual disabilities as their target population. This research pointed to the lack of a critical reflection on the organization of inclusive schools. However, there remains a shortage of studies following school experiences about the education of students with disabilities from the perspective of school inclusion in Brazil, especially in the interface with professional education.

Keywords: Inclusion, disabled students, and teacher training. 


\section{Introdução}

Segundo Brasil (2011), 20\% da população mundial apresenta algum tipo de deficiência. No Brasil, este índice sobe para 14\%. De acordo com dados da Secretaria de Educação Especial (BRASIL, 2008), em 2008, cerca de 366 mil estudantes com deficiência cursavam o Ensino Fundamental, mas somente 1,6\% deste número de estudantes chegava ao Ensino Médio.

No entanto, de acordo com os resultados do Censo Escolar, no período de 2003 a 2015, em relação às matrículas de estudantes com deficiência na Educação Básica, houve uma evolução nas matrículas de 504.039, em 2003, para 930.683, em 2015, expressando um crescimento de $85 \%$. No que se refere ao ingresso em classes comuns no ensino regular, verifica-se um crescimento de 425\%, passando de 145.141 estudantes, em 2003, para 760.983, em 2015 (BRASIL, 2016). Quanto à distribuição dessas matrículas nas esferas pública e privada, em 2003, registravam-se 276.261 (53,2\%) estudantes na rede pública e 227.778 $(46,8 \%)$ nas escolas privadas, principalmente em instituições especializadas em filantropia. Com o desenvolvimento das políticas de educação inclusiva nesse período, evidencia-se um crescimento de $172 \%$ das matrículas nas escolas públicas, que alcançam 751.747 (81\%) estudantes, em 2015.

Aliado a esse crescimento nas matrículas deste público alvo, nos últimos anos é percebida a ampliação das discussões abordando a inclusão escolar e social e, consequentemente, cresce o número de instituições que estão se (re)estruturando a fim de se tornarem mais democráticas, e, portanto, inclusivas. Entretanto, pode-se verificar que a não discriminação quanto à matrícula na escola regular não implica, necessariamente, a inexistência do preconceito na sociedade.

Percebe-se também, de acordo com dados do Censo Escolar (INEP, 2010), que as famílias dos estudantes com deficiência estão reafirmando seus direitos, garantidos constitucionalmente, matriculando crianças e jovens nestas condições nas escolas regulares, havendo, por isso, um crescimento do número de matrículas.

Esse aumento significativo no número de matrículas destes estudantes vem exigindo das instituições de ensino das várias esferas um repensar, uma reestruturação da escola para o pleno atendimento a esses estudantes e para a efetivação de uma escola solidária para todos, na busca por uma sociedade realmente acolhedora.

O atendimento aos estudantes com deficiência está legitimado em vários dispositivos legais nacionais e internacionais que preconizam sua matrícula na rede regular de ensino. A lei que assegura o direito aos estudantes com deficiência de estudarem em escolas regulares no Brasil é de 1996, e em setembro de 2001, por meio de uma resolução do Ministério da 
Educação, foram estabelecidas normas para adaptações das unidades de ensino obrigando-as a receber matrícula de qualquer pessoa com alguma deficiência.

Contudo, o que se observa nas diversas instâncias sociais e, principalmente, nas escolas, são manifestações de preconceito contra as pessoas com deficiência física, intelectual, visual, auditiva, pessoas com condutas típicas e com altas habilidades, somando-se a isso a falta de formação dos professores e a ausência de discussões neste contexto.

Estudos recentes (AINSCOW, 2002; DAMASCENDO, 2010; MASINI, 2007) analisam a importância do papel dos profissionais da escola que terão a responsabilidade de educar os estudantes que apresentam deficiências nesse processo de inclusão. Segundo Steinback e Steinback (2004), os administradores educacionais são facilitadores do desenvolvimento e da implementação, e não os criadores da legislação. Os estudantes e o professor, e não o sistema, têm o poder de efetivar a criação de escolas acolhedoras e, portanto, inclusivas. De acordo com esta ideia, é possível assegurar que, embora documentos oficiais regulamentem e fundamentem a inclusão, a sua efetivação está associada à prática cotidiana no âmbito escolar, ou seja, é na escola que as políticas se concretizam e percebe-se aí a existência de práticas que ainda deixam a desejar.

A inclusão de pessoas com deficiência na rede regular de ensino tem assumido uma importante posição nos debates educacionais nacionais e internacionais. No Brasil, inúmeros dispositivos legais, materializados sob a forma de documentos e diretrizes, fazem referência aos direitos dessas pessoas. Vale destacar a Lei de Diretrizes e Bases da Educação Nacional, Lei Federal nº. 9394/96, que, em seu capítulo V, determina que a Educação Especial deva ser "oferecida preferencialmente na rede regular de ensino, para educandos portadores de necessidades especiais". Nesse mesmo capítulo, o documento salienta que os sistemas de ensino asseguram a tais estudantes "currículos, métodos, técnicas, recursos educativos e organização específicos para atender às suas especificidades” (BRASIL, 1996, p.19).

Ainda nessa direção, cabe mencionar as Diretrizes Nacionais para Educação Especial na Educação Básica (BRASIL, 2001) e a Política Nacional de Educação Especial na Perspectiva da Educação Inclusiva (BRASIL, 2008). As Diretrizes Nacionais para a Educação Especial regulamentam a organização e a função da Educação Especial nos sistemas de ensino da Educação Básica e os locais de atendimento, bem como as propostas de flexibilização e adaptação curricular em nosso país. Já a Política Nacional da Educação Especial na Perspectiva da Educação Inclusiva (BRASIL, 2008) é evidenciada como parte do Plano de Metas Compromisso Todos pela Educação (BRASIL, 2007), que pretende garantir o acesso e a permanência dos estudantes no ensino regular e o atendimento às necessidades específicas desses estudantes, fortalecendo seu ingresso nas escolas públicas por meio da implantação de salas de recursos multifuncionais, da acessibilidade arquitetônica dos prédios escolares, do acesso e da permanência na Educação Superior, entre outras medidas. Tais aspectos são 
reforçados pelas Diretrizes Operacionais para o Atendimento Educacional Especializado na Educação Básica, modalidade Educação Especial (BRASIL, 2009).

Porém, apesar dos avanços nas Políticas Públicas para a garantia dos direitos educacionais e sociais de pessoas com deficiência e do efetivo aumento do número de suas matrículas na escola regular, na prática, as instituições escolares enfrentam inúmeros problemas, tensões e contradições. Pesquisadores como Ainscow (2002), Costa (2007, 2009), Damasceno (2006, 2010), entre outros, ressaltam que, apesar de a proposta de inclusão ser reconhecida como um ressignificar da concepção de educação até então possível, muitas são as barreiras que impedem sua implementação na realidade escolar brasileira. Então, reiterase e levanta uma problemática a ser analisada e pesquisada com o objetivo de investigar o processo de inclusão de estudantes com deficiência nas instituições brasileiras de ensino.

Nesse sentido, é que se fundamenta esta pesquisa que pretende responder às seguintes questões:

a) Está ocorrendo o acolhimento de estudantes com deficiência visual no IFMG Campus São João Evangelista?

b) Como a Instituição pesquisada vem atuando diante desse movimento de inclusão escolar da contemporaneidade?

c) Como os docentes que vêm atuando com estudantes com deficiência visual no Ensino Técnico da Instituição pesquisada reconhecem a diferença e a diversidade que ali se fazem presentes?

Espera-se que o resultado desta pesquisa possa contribuir para novos diálogos e ponderações que discutam a inclusão de estudantes com deficiência visual, sobretudo nas Instituições Federais de Educação Profissional do Brasil. Para além disso, espera-se que este estudo possa levantar uma problematização do processo de inclusão de estudantes com deficiência, tendo como foco o reconhecimento e a aceitação do diferente/diversidade na formação docente e nas experiências destes profissionais.

\section{Desenvolvimento}

Para subsidiar a análise dos dados da pesquisa que tem como base a formação e as experiências de docentes que atuam com estudantes com deficiência visual na Instituição pesquisada, pretende-se desenvolver e discutir aqui as contribuições teóricas que abordam o tema.

Dessa forma, em atendimento aos objetivos propostos para o estudo, este item é constituído de três subitens, onde o primeiro discute em que sentido deve ocorrer a formação docente para que possam atuar diante da carência de acolhimento de estudantes com 
deficiência e da aceitação da diferença e da diversidade presentes no ser humano. No segundo subitem, são apresentados os resultados coletados na pesquisa, no sentido de investigar como a instituição pesquisada vem atuando diante desse movimento de inclusão escolar na contemporaneidade, ou seja, como os estudantes com deficiência vêm sendo acolhidos no cenário pesquisado. E, por fim, no último subitem, no sentido de analisar os resultados coletados na pesquisa, busca fazer aproximações das concepções dos docentes pesquisados com o reconhecimento da diferença e da diversidade ali presentes e o que se pode intitular de inclusão e acolhimento de estudantes com deficiência visual.

\section{Inclusão, Diferença, Diversidade e Formação Docente}

Sei que não sou um garoto normal de dez anos comum. Quer dizer, é claro que faço coisas comuns. [...] Mas sei que crianças comuns não fazem outras crianças comuns saírem correndo e gritando do parquinho. Sei que os outros não ficam encarando as crianças comuns aonde quer que elas vão. (PALÁCIO, 2014, p.10).

Veiga-Neto (2011), discute algumas das dificuldades que enfrentam as políticas pela inclusão escolar, a começar pela construção moderna da normalidade. O autor parte do princípio de que evitar o uso de termos como 'normal' e 'anormal' exprime a urgência de se discutir a presença e a utilização, nas nossas práticas e relações cotidianas, desses mesmos conceitos.

A maior dificuldade, portanto, está no próprio discurso da anormalidade: não há vontade política suficiente que supere uma formação cultural (e consequentemente também profissional) de afastar e calar as diferenças. A diferença perturba as pessoas e no mundo de hoje é evidente como a presença de outros que não sejam idênticos a "todos" - que estão presos a uma noção ilusória de normalidade - incomoda a própria existência (FERRE, 2011, p.198). Afinal, "nada há de tão perturbador como aquilo que a cada um lembra seus próprios defeitos, suas próprias limitações, suas próprias mortes” (Idem).

A perturbação com a diferença está tão enraizada nas práticas cotidianas e discursos que, nos próprios estudos a favor da diversidade, identifica-se que este conceito está diretamente ligado à noção de que ele é atributo exclusivo da alteridade. Um pensamento autocêntrico, de que eu sou a norma e o outro é a diferença (SKLIAR, 2003; PIERUCCI, 1999). De acordo com Silva (2012, p.83):

[...] fixar uma determinada identidade como a norma é uma das formas privilegiadas de hierarquização das identidades e das diferenças. A normalização é um dos processos mais sutis pelos quais o poder se manifesta no campo da identidade e da diferença. Normalizar significa eleger - 
arbitrariamente - uma identidade específica como parâmetro em relação ao qual as outras identidades são avaliadas e hierarquizadas.

O autor expõe a relação existente entre uma identidade que passa a ser considerada como "normal" em detrimento da outra identidade - a diferente - por meio das manifestações do poder. Acredita-se que, somente ultrapassando a relação hierárquica e normalizadora e partindo para uma postura e uma ação que se interessem e valorizem a diversidade, é que seja possível o início da superação dos dilemas da Inclusão.

Nesse contexto, aponta-se o trabalho de Melero (2001), que defende uma pedagogia de elogio à diferença, que entende a diversidade como algo genuinamente humano: um elemento de valor e não de segregação. Assim como Sacristán (2002) fala dos diferentes níveis de aproximação e convivência com a diversidade (compreender, aceitar e se interessar), Melero (2001, p.31) antecipa a construção de uma nova cultura que conheça, compreenda, respeite e valorize "cada ser humano como ele é e não como gostariam que ele fosse, uma vez que o mais belo que existe no ser humano é a diferença entre eles".

Melero (2001, p.49) ainda defende uma cultura da diversidade, que vai para além da filosofia da integração e isso significa uma mudança de postura da sociedade, de tal modo que: “[...] o pensamento pedagógico do professorado vá se transformando e, assim, considere as pessoas diferentes cognitiva, social, de gênero, linguística, cultural e etnicamente como ocasiões para melhorar sua prática profissional e não ocasiões para estabelecer desigualdades”.

Para tanto, é eminente a construção de uma nova cultura escolar, que aprecie a diferença, que forme homens e mulheres sensíveis a esse conceito e não apenas meros entendedores dele. Que forme professoras e professores para uma prática pedagógica enriquecedora, emancipadora e libertadora.

Considerando o exposto e os objetivos deste estudo, verifica-se o estabelecimento de um pensamento crítico que problematiza as práticas docentes frente à demanda por inclusão escolar na instituição pesquisada, recorrendo às análises constituídas no cotidiano escolar, que revelem a aceitação do diferente como "normal" e ainda os aspectos pedagógicos e atitudes que obstaculizam o atendimento das demandas educacionais e pedagógicas dos estudantes com deficiência. Para balizar essa análise, recorremos ao pensamento do filósofo Theodor Adorno (1995, p.121), que evidencia a emancipação e ainda assevera: “[...] é necessário contrapor-se a tal ausência de consciência, é preciso evitar que as pessoas golpeiem para os lados sem refletir a respeito de si próprias. A educação tem sentido unicamente quando dirigida a uma autoreflexão crítica”.

Assim, o autor sustenta a necessidade de pensar a prática docente e direciona o trabalho do educador de forma a tornar o indivíduo reflexivo e crítico sobre a sua realidade, transformando-o num ser capaz de ser construtor de suas ideias e de se libertar de conceitos considerados como prontos e verdadeiros. Aliado a isso, o mesmo autor considera uma meta 
importante para aqueles que pretendem ensinar alguém: “[...] a obrigação de desprovincializar ao invés de imitar ingenuamente o que é considerado culto deveria constituir uma meta importante para aqueles que pretendem ensinar alguém” (ADORNO, 1995, p. 67).

O autor evidencia o papel fundamental da educação no processo de emancipação do indivíduo. Ainda na perspectiva de Adorno, o indivíduo é um ser social e a emancipação é um pressuposto da democracia que se molda na formação da vontade individual de cada ser como um indivíduo autônomo. A educação deve, portanto, contribuir para o processo de formação e emancipação, para criar condições em que os indivíduos, socialmente, conquistem a autonomia.

Nessa perspectiva, Becker, citado por Adorno (1995, p.177), destaca a importância da figura dos professores para os estudantes. Para ele:

Creio que é importante fixarmos esta questão: que evidentemente o processo de rompimento com a autoridade é necessário, porém que a descoberta da identidade, por sua vez, não é possível sem o encontro com a autoridade. Disto resulta uma série de consequências muito complexas e aparentemente contraditórias para a elaboração de nossa estrutura educacional. Afirma-se que não tem sentido uma escola sem professores, mas que, por sua vez, o professor precisa ter clareza quanto a que sua tarefa principal consiste [...].

Desta forma, o autor problematiza a participação do professor em todo o processo, tornando relevante que ele tenha consciência de seu papel que vai além da reprodução, se firmando como um exemplo autônomo e atuante na construção de personalidades autônomas. Nessa direção, Damasceno (2006, p.58) atesta que:

[...] é possível pela educação possibilitarmos uma formação emancipatória, desde que se tenha clareza desse objetivo e dessa possibilidade. Se o processo educacional encontra-se obscurecido quanto às suas orientações emancipatórias, os sujeitos participantes do processo - professores e estudantes, deficientes e não deficientes, é que deverão, pela crítica reflexiva, instância possível de resistência à barbárie, resistir à sua reprodução e manutenção.

O autor expõe uma formação que possibilite desenvolver espírito crítico, investigativo e autônomo mediante a realidade vivida e que disponha a realizar experiências que formem uma consciência verdadeira no sentido de contribuir para transpor as barreiras e os desafios que surgirão no processo educacional inclusivo.

Diante do exposto, constata-se carência de pensamento crítico sobre a organização de escolas inclusivas para o acolhimento de estudantes com deficiência, o que poderá se dar por meio de uma formação para a emancipação e da aceitação das diferenças humanas.

\section{Experiências in loco: inclusão no cenário da pesquisa}


O locus deste estudo foi um Instituto Federal do Estado de Minas Gerais, autarquia criada juntamente com outras 37 instituições do país por meio da Lei $\mathrm{n}^{0} 11.892^{5}$, sancionada em 29 de dezembro de 2008, pelo Presidente da República. Os Institutos Federais são instituições pluricurriculares e multicampi e foram criados com o objetivo de oferecer Educação Básica, profissional e superior nas diversas modalidades de ensino. A instituição pesquisada conta hoje com onze Campi, com um total de aproximadamente dez mil estudantes, e tem a sua reitoria instalada na cidade de Belo Horizonte, capital do Estado de Minas Gerais. Os seus Campi estão localizados em cidades diferentes da região sudeste, sendo eles: Campus Bambuí, Campus Betim, Campus Congonhas, Campus Formiga, Campus Governador Valadares, Campus Ouro Branco, Campus Ouro Preto, Campus Ribeirão das Neves, Campus Sabará, Campus Santa Luzia e Campus São João Evangelista.

Este estudo foi realizado em um dos onze Campi que constituem a instituição pesquisada e teve como um dos elementos motivadores, o fato de que, no início do ano letivo de 2005, o referido Campus recebeu matrícula de uma estudante com deficiência física, que usava cadeira de rodas para se locomover, e isso trouxe apreensão para todos os profissionais da instituição, em função da situação nova e desafiadora para todos os que ali trabalhavam e estudavam.

Parte desta apreensão foi se reduzindo a partir do momento em que a própria estudante e seus colegas foram revelando aos professores e demais estudantes como atuar e conviver com este cenário. Diante disso, ficou clara a importante representação que os próprios estudantes com deficiência naturalmente poderão assumir, atuando como fonte rica de experiência e de convivência no cotidiano da escola, se revelando como elemento primário para a aprendizagem coletiva dos estudantes com e sem deficiência e dos profissionais da área pedagógica e administrativa que atuarão diretamente no processo educacional.

A chegada da estudante usuária de cadeira de rodas no Campus pesquisado levou à administração a tomar providências visando criar, pelo menos, o mínimo de acesso aos diversos espaços físicos da instituição, considerando que a construção era antiga e, portanto, não existia acessibilidade física e arquitetônica. Torna-se relevante destacar que tais iniciativas se reduziram às melhorias na infraestrutura da instituição.

Aliado a isso, já no ano de 2010, foi verificado, também no Campus São João Evangelista, no Curso Técnico em Nutrição e Dietética, as matrículas de um estudante cego e de cinco estudantes com visão bastante reduzida. Inicialmente, mesmo após ter vivenciado a situação anterior com a estudante usuária de cadeira de rodas, essa situação deixou a comunidade escolar muito apreensiva. A inexistência de estruturas didático-pedagógicas adequadas para receber pessoas com deficiências, de ordem sensorial ou física, além da ausência de profissionais especializados a oferecer a esses estudantes uma educação que os

5 http://www.camara.gov.br/sileg/integras/724044.pdf 
oferecesse condições de aprendizagem iguais aos que não possuíam deficiência, gerou receio e conflitos.

Diante das situações expostas, constatou-se a inexistência de acessibilidade no espaço escolar, em suas múltiplas dimensões (físico-arquitetônica, didático-pedagógica, curricular, entre outras) que constituem, por assim dizer, "pré-requisitos para o processo ensinoaprendizagem de alunos com deficiência no ensino regular" (FERNANDES, ANTUNES; GLAT, 2009, p.58).

Entende-se, nesse sentido, que a criação das condições de acessibilidade está relacionada ao atendimento de efetivas políticas públicas voltadas para a inclusão de estudantes com deficiência, ratificando o respeito e o acolhimento das diferenças humanas em uma escola que se estrutura/constitui/fundamenta no convívio com a diversidade como fonte primária de aprendizagem com as diferentes subjetividades humanas. Isso requer repensar a escola que temos, a fim de sua reestruturação, que vai muito além da inserção de algumas medidas adicionais que, em síntese, mantém a escola contemporânea seletiva e segregada.

No cotidiano escolar, vários aspectos têm sido observados em relação à capacitação dos profissionais que atuam com estes estudantes nas classes regulares, à qualificação do profissional que poderá dar suporte/apoio aos professores que atuam nas classes regulares, e a outros desafios que se apresentam no atendimento às demandas pedagógicas e educacionais dos estudantes com deficiência.

A escola pública, sob a égide das políticas públicas, vem buscando tornar-se um espaço que possibilita que todos os estudantes sejam acolhidos, independentemente de suas condições socioeconômicas, raciais, culturais ou de desenvolvimento; mas o cotidiano escolar ainda impõe muitas barreiras que remetem aos limites sociais. De acordo com a Declaração de Salamanca (UNESCO, 1994), as escolas regulares devem se adaptar para atender às necessidades específicas dos estudantes, pois elas se constituem nos ambientes mais capazes para combater as atitudes discriminatórias e, como consequências, podem auxiliar na construção de uma sociedade inclusiva atingindo uma educação para todos.

No entanto, de acordo com pesquisas de Ainscow (2002), Costa (2007) e Damasceno (2006), percebe-se que estudantes com deficiência são matriculados em escolas regulares desconsiderando as suas diferenças. Essas mesmas pesquisas ainda apontaram a realização de um planejamento único para todos os estudantes das turmas, gerando, assim, a segregação.

Dessa maneira, entende-se que para que as escolas públicas sejam acolhedoras no atendimento aos estudantes com deficiências, primeiramente devem buscar refletir e reconhecer a realidade vivida, de forma a levar em consideração a diversidade presente e o equilíbrio entre o coletivo e o particular como pressupostos para a manutenção do respeito, do reconhecimento e da aceitação das diferenças existentes como características humanas. 
$\mathrm{Na}$ direção do objetivo desse trabalho de pesquisa, buscou-se apoio também em Masini (2007), quando atesta que, para a efetivação da inclusão nas escolas, torna-se necessária uma mudança no modo de pensar, de aceitar, de planejar e de avaliar, destacando, assim, a importância da gestão e da prática docente no processo.

\section{O outro lado da fronteira: aproximações docentes com a inclusão de estudantes com deficiência visual}

A população-alvo desta pesquisa se constituiu em sete professoras do Curso Técnico em Nutrição e Dietética que atuavam com estudantes com deficiência visual. As professoras, após assinarem o Termo de Livre Consentimento para a participação na pesquisa, responderam a questionários semiestruturados para a caracterização dos sujeitos da pesquisa e, após, foram realizadas entrevistas semiestruturadas com todas as participantes.

Os dados coletados revelaram que as professoras, sujeitos deste estudo, atuam nas três séries do referido curso, que possuem estudantes com deficiência visual (cegueira e baixa visão) incluídos em salas regulares do curso e convivendo com os demais estudantes.

Todas as professoras entrevistadas responderam que, em função das exigências do próprio cargo e do nível de ensino que a instituição oferece, têm formação em nível de graduação. Todas as entrevistadas declararam terem realizado cursos de pós-graduação em nível de Especialização, e dentre as sete professoras, seis são mestras. Com relação às experiências acadêmico-formativas que abordam questões sobre Educação Inclusiva, quatro delas asseguraram terem participado de encontro/seminário/palestra/curso que tenha debatido o processo de inclusão de estudantes com deficiência. Duas professoras testemunharam que não participaram de encontro/seminário/palestra/curso que tenha debatido o processo de inclusão, mas, ao mesmo tempo, mencionaram terem realizado curso de aperfeiçoamento do Sistema Braille oferecido pela própria instituição pesquisada. Dentre as professoras, duas delas afirmaram não terem participado de cursos desta natureza.

Esse quadro de respostas expõe a existência de uma preocupação da Instituição pesquisada em oferecer cursos, ainda que em caráter emergencial, para os professores, e isso é um fator relevante para a sua organização inclusiva.

Para complementar os dados coletados da pesquisa, realizou-se entrevista com a Coordenadora Geral de Ensino que certificou que a instituição ofereceu, no ano de 2010, o Curso do sistema Braille a todos os professores interessados em realizá-lo, priorizando os professores que estavam atuando com o estudante cego, recém-matriculado na Instituição. No entanto, a Coordenação garantiu que alguns professores que iriam atuar com aquele aluno não se interessaram ou não consideraram importante realizar tal curso, o que ocasionou 
disponibilidade de vagas que foram ofertadas para outros professores interessados que não atuavam ou iriam atuar com o referido estudante.

Um fato interessante observado durante a entrevista foi que duas professoras mencionaram terem realizado curso do Sistema Braille, mas quando foram inquiridas sobre a sua participação em algum encontro/seminário/palestra/curso que tenha debatido o processo de inclusão de estudantes com deficiência, as mesmas responderam negativamente à questão, ou seja, essas professoras não reconheceram um curso do Sistema Braille como um curso que se relaciona com a prática da Educação Inclusiva.

De maneira geral, as professoras entrevistadas, no que se refere à formação acadêmica, manifestaram terem tido a oportunidade de vivenciar momentos e/ou de participar de evento que debatesse a inclusão escolar.

Uma das professoras participantes do estudo fez considerações mais abrangentes sobre a importância da inclusão escolar no atual cenário educacional, e, ao mesmo tempo cogitou sobre a importância de uma especialização ou aperfeiçoamento docente em serviço para o melhor atendimento das demandas pedagógicas e educacionais dos estudantes com deficiência.

\section{Considerações}

O exposto deixa clara a carência de pensamento crítico e amplo que reflita sobre a organização de escolas inclusivas para o acolhimento de estudantes com deficiência, o que pode se dar por meio de uma formação para a emancipação. Isso, nas palavras de Adorno (1995), requer um posicionamento assertivo dos profissionais envolvidos no processo de busca de uma educação crítica, o que contribui para transpor as barreiras e os desafios que surgem em função da promoção da inclusão de estudantes com deficiência.

Entende-se, então, que os professores devem ser apoiados em seus processos de formação profissional com vistas à inclusão e ao acolhimento de estudantes com deficiência na escola. Partindo desse pressuposto e ao fazer uma análise acurada dos dados coletados neste estudo, observa-se a privação destes espaços de formação e de discussão que oportunizem debates abordando questões referentes à Educação Inclusiva, tais como: o que estamos entendendo como sendo esse movimento de inclusão escolar? Qual o papel da escola diante desse movimento de inclusão escolar? Qual a concepção dos docentes sobre as diferenças humanas e a diversidade em sua sala de aula? Quais os pressupostos para uma formação de professores que seja pautada na autonomia e na emancipação?

Essas discussões e debates poderão definir caminhos e possibilidades para a superação de limites existentes que vêm dificultando o processo de acolhimento de estudantes 
com deficiência na escola e, por isso, este estudo não se encerra aqui. Uma consideração importante, dentre outras, é que há, ainda, escassez de estudos resultantes de experiências docentes sobre a educação dos estudantes com deficiência na perspectiva da inclusão escolar no Brasil, sobretudo em interface com a Educação Profissional. Um estudo como este possibilitará divulgar e conhecer diferentes realidades do Brasil, um país de dimensões continentais e com grandes injustiças sociais e educacionais.

Portanto, observa-se a urgência de resistir e de superar a alienação imposta às professoras e professores brasileiros pelo sistema social neoliberal, por intermédio de uma formação para a homogeneização e da não aceitação das diferenças humanas como características individuais. Nesse caso específico, foi revelada que a reprodução da exclusão escolar de estudantes com deficiência está presente, de maneira enfática, neste estudo.

\section{Referências}

ADORNO, T. W. Educação e Emancipação. São Paulo: Paz e Terra, 1995.

AINSCOW, M. Educação para todos: torná-la uma realidade. In: Caminhos para as escolas inclusivas. Lisboa: Instituto de Inovação Educacional, p. 11-28, 2002.

BRASIL. Câmara de Educação Básica do Conselho Nacional de Educação. Resolução n. 2, de 2001. Institui Diretrizes Nacionais para a Educação Especial na Educação Básica. Brasília, DF: 2001. DEC, Disponível em < http://portal.mec.gov.br/cne/arquivos/pdf/CEBo201.pdf>. Acesso em 12 abr. 2016.

BRASIL. Casa Civil. Decreto $n^{o}$. 6.094, de 24 de abril de 2007. Dispõe sobre a implementação do Plano de Metas Compromisso Todos pela Educação, pela União Federal, em regime de colaboração com Municípios, Distrito Federal e Estados, e a participação das famílias e da comunidade, mediante programas e ações de assistência técnica e financeira, visando a mobilização social pela melhoria da qualidade da educação básica. Brasília, DF: Casa Civil, 2007. Disponível em: $<$ http://www.planalto.gov.br/ccivil_03/_ato20072010/2007/decreto/d6094.htm>. Acesso em: 13 de maio de 2016.

BRASIL. INEP. Censo Escolar da Educação Básica. Brasília: INEP, 2010. Disponível em: <http://portal.inep.gov.br/basica-censo>. Acesso em: 13 de novembro de 2010.

BRASIL. Ministério da Educação e Cultura. A Consolidação da Inclusão Escolar no Brasil $2003 \quad 2016.2016 .2$ Disponível $<$ https://inclusaoja.files.wordpress.com/2016/o5/a-consolidac3a7c3a3o-dainclusc3a3o-escolar-no-brasil-2003-a-2016.pdf>. Acesso em: 16 de maio de 2016. 
BRASIL. Ministério da Educação e Cultura. Lei n.9394/96, de 20 de dezembro de 1996. Lei de Diretrizes e Bases da Educação Nacional. Brasília, DF: MEC, 1996.

BRASIL. Legislação Citada Anexada Pela Coordenação De Estudos Legislativos - CEDI, Lei n. 11.892/20o8, de 20 de dezembro de 2008. http://www.camara.gov.br/sileg/integras/724044.pdf

BRASIL. Ministério da Educação. Secretaria de Educação Especial. Política Nacional de Educação Especial na perspectiva da Educação Inclusiva. Brasília: MEC, SEE, 2008. Disponível em: <http://portal.mec.gov.br/arquivos/pdf/politicaeducespecial.pdf>. Acesso em: 23 de maio de 2016.

BRASIL. Resolução $n^{o}$ 4, de 2 de outubro de 2009. Diretrizes Operacionais para o Atendimento Educacional Especializado na Educação Básica, modalidade Educação Especial. Institui Diretrizes Operacionais para o Atendimento Educacional Especializado na Educação Básica, modalidade Educação Especial. Brasília: MEC, 2009. Disponível em: <http://www.abiee.org.br/doc/Resolu\%E7\%E30\%204\%20DE\%2002\%20out\%2020 09\%20EDUCA\%C7\%C3O\%2oESPECIAL\%2orcebo04_09.pdf $>$. Acesso em: 12 de maio de 2016.

COSTA, V. A. da. Os processos de inclusão dos alunos com necessidades educativas especiais: políticas e sistemas. Rio de Janeiro: UNIRIO/CEAD, 2007.

COSTA, V. A. da. Políticas públicas de educação e formação de professores: experiências de inclusão dos alunos com deficiência na escola pública. In: CHAVES, I. M.; COSTA, V. A. da; CARNEIRO, W. (Orgs.). Políticas públicas de educação: pesquisas em confluência. Niterói: Intertexto, 2009.

DAMASCENO, A. R. A formação de professores e os desafios para a escola inclusiva: as experiências da Escola Municipal Leônidas Sobrino Porto. Dissertação (Mestrado em Educação) - Universidade Federal Fluminense. Niterói - Rio de Janeiro, 2006.

DAMASCENO, A. R. Educação inclusiva e organização da Escola: Projeto pedagógico na perspectiva da teoria crítica. Tese (Doutorado em Educação) - Universidade Federal Fluminense. Niterói - Rio de Janeiro, 2010.

FERNANDES, E. M.; ANTUNES, K.; GLAT, R. Acessibilidade ao currículo: pré-requisito para o processo ensino-aprendizagem de alunos com necessidades educacionais especiais no ensino regular. In: GLAT, R. (org.). Educação Inclusiva: cultura e cotidiano escolar. Rio de Janeiro: Editora 7 letras, 2009. p.53-64.

FERRE, N. P. L. Identidade, diferença e diversidade: manter viva a pergunta. In: LARROSA, Jorge; SKLIAR, Carlos (Org.). Habitantes de Babel: políticas e poéticas da diferença. Belo Horizonte: Autêntica, 2011. p.195-214. 
MASINI, E. F. S. (Org.). A Pessoa com deficiência visual: um livro para educadores. São Paulo: Vetor, 2007.

MELERO, M. La cultura de la diversidad o el elogio de la diferencia y la lucha contra las desigualdades. In: COMPAÑE, Antonio (Org). Educar para la diversidad en el siglo XXI. Zaracoza/Espanha: Mira Editores, 2001.

PALACIO, R. J. Extraordinário. Tradução Rachel Agavino. 2.ed. Rio de Janeiro: Intrínseca, 2014.

PIERUCCI, A. F. Ciladas da diferença. São Paulo: Editora 34, 1999.

SACRISTÁN, J. Educar para viver com os outros: os vínculos culturais e as relações sociais. In: Educar e conviver na cultura global: as exigências da cidadania. Trad. Ernani Rosa. Porto Alegre: Artmed, 2002.

SILVA, T. T. da (Org). Identidade e diferença: a perspectiva dos estudos culturais. São Paulo: Vozes, 2012.

SKLIAR, C. Pedagogia (improvável) da diferença: e se o outro não estivesse aí? Trad. Giane Lessa. Rio de Janeiro: DP\&A, 2003.

STAINBACK, S.; STAINBACK, W. Inclusão: um guia para educadores. Trad. Magda França Lopes. Porto Alegre: Artes Médicas Sul, 2004.

UNESCO. Declaração de Salamanca e linha de ação sobre necessidades educativas especiais. Brasília: CORDE, 1994.

VEIGA-NETO, A. Incluir para excluir. In: LARROSA, Jorge; SKLIAR, Carlos (Org.). Habitantes de Babel: políticas e poéticas da diferença. Belo Horizonte: Autêntica, 2011. p.105-118.

\section{Agradecimentos}

Agradecemos o apoio financeiro recebido da Coordenação de Aperfeiçoamento de Pessoal de Nível Superior - CAPES - Brasil, por meio do Projeto Observatório da Educação (Convênio ou AUXPE n. ${ }^{\text {o: }}$ OE 99/10), bem como a disponibilidade das escolas parceiras deste projeto.

\section{Biografia Resumida}

Cláudia Marisa Ferreira Machado Pimenta - Licenciatura em História pela Faculdade de Ciências e Letras de Caratinga-MG, Mestre em Educação Agrícola (PPGEA/UFRRJ) com foco na Inclusão Escolar. Doutoranda em Educação (PPGE/UFBA). 
Atualmente é professora do Ensino Básico, Técnico e Tecnológico do Instituto Federal Minas Gerais - Campus São João Evangelista. Currículo Lattes: http://lattes.cnpq.br/o898782872957954 Contato: claudia.machado@ifmg.edu.brceno@hotmail.com

Allan Rocha Damasceno - Licenciatura em Física pela Universidade Federal do Rio de Janeiro; Especialista, Mestre e Doutor em Educação pela Universidade Federal Fluminense. Professor Adjunto do Departamento de Teoria e Planejamento de Ensino do Instituto de Educação da Universidade Federal Rural do Rio de Janeiro (UFRRJ).

Currículo Lattes: http://lattes.cnpq.br/o177717397152120

Contato: allan_damasceno@hotmail.com

Amparo Villa Cupolillo - Licenciatura em Educação Física pela Universidade Federal Rural do Rio de Janeiro, Mestre Desenvolvimento, Agricultura e Sociedade pela Universidade Federal Rural do Rio de Janeiro. Doutora em Educação pela Universidade Federal Fluminense. Professora Adjunta do Departamento de Teoria e Planejamento de Ensino do Instituto de Educação da Universidade Federal Rural do Rio de Janeiro (UFRRJ).

Currículo Lattes: http://lattes.cnpq.br/5482837394103537

Contato: amparo@ufrrj.br 